Dominance and Innovation

Chander Velu and Sriya Iyer

January 2010

CWPE 1009 


\title{
Dominance and Innovation
}

\author{
Chander Velu ${ }^{1}$ and Sriya Iyer $^{2}$
}

Do dominant or less dominant firms innovate more? Theoretically it has been shown that within an asymmetric mixed strategy game of a patent race, the less dominant firm invests more than the dominant firm. But the empirical data on patent races is divided. In this paper, we argue that the decisions that concern strategic choice in innovation may be influenced by expected relative returns. Our approach, which we call the returns-based beliefs approach, is based upon subjective probabilities. It combines a decision analytic solution concept and Luce's (1959) probabilistic choice model. In particular, we show how the use of the returns-based beliefs approach provides support for the thesis that dominant firms invest more in R\&D within an asymmetric mixed strategy game. Consequently, we argue that the returns-based beliefs approach is more in line with recent empirical studies of innovation. We also provide empirical evidence using UK R\&D data across a range of industries from 2001-2006 that shows that firms' spending on $R \& D$ is related more to their own profitability than that of their competitors, which is consistent with the returns-based beliefs approach. We discuss the managerial implications of our theoretical approach and the empirical findings.

\footnotetext{
${ }^{1}$ Judge Business School, University of Cambridge, Trumpington Street, Cambridge, CB2 1AG, United Kingdom. c.velu@jbs.cam.ac.uk

${ }^{2}$ Faculty of Economics, University of Cambridge, Sidgwick Avenue, Cambridge CB3 9DD, United Kingdom. sriya.iyer@econ.cam.ac.uk
} 


\section{Introduction}

Microsoft, the largest firm in the software industry, is often regarded as one of the most aggressive innovators. It can be argued that its aggressive innovative stance is partly responsible for the persistence of its large market share in the software industry. On the other hand, Kodak, the most dominant firm in traditional film photography was relatively slow in embracing the innovations in photography afforded by digital technology. The relatively lethargic response of Kodak allowed Canon and Sony to capture the initial market for digital photography (IRI and Morgan Stanley Equity Research 2003). These observations show that the relationship between dominance and innovation is not intuitively obvious. The academic literature on this topic reflects this. One of the most contentious and widely-debated issues is whether dominant firms will innovate in order to maintain their dominant position (Lerner 1997). On this issue the academic literature depicts sharply contrasting theoretical and empirical evidence.

\section{Figure 1: Allocation of innovation spending}

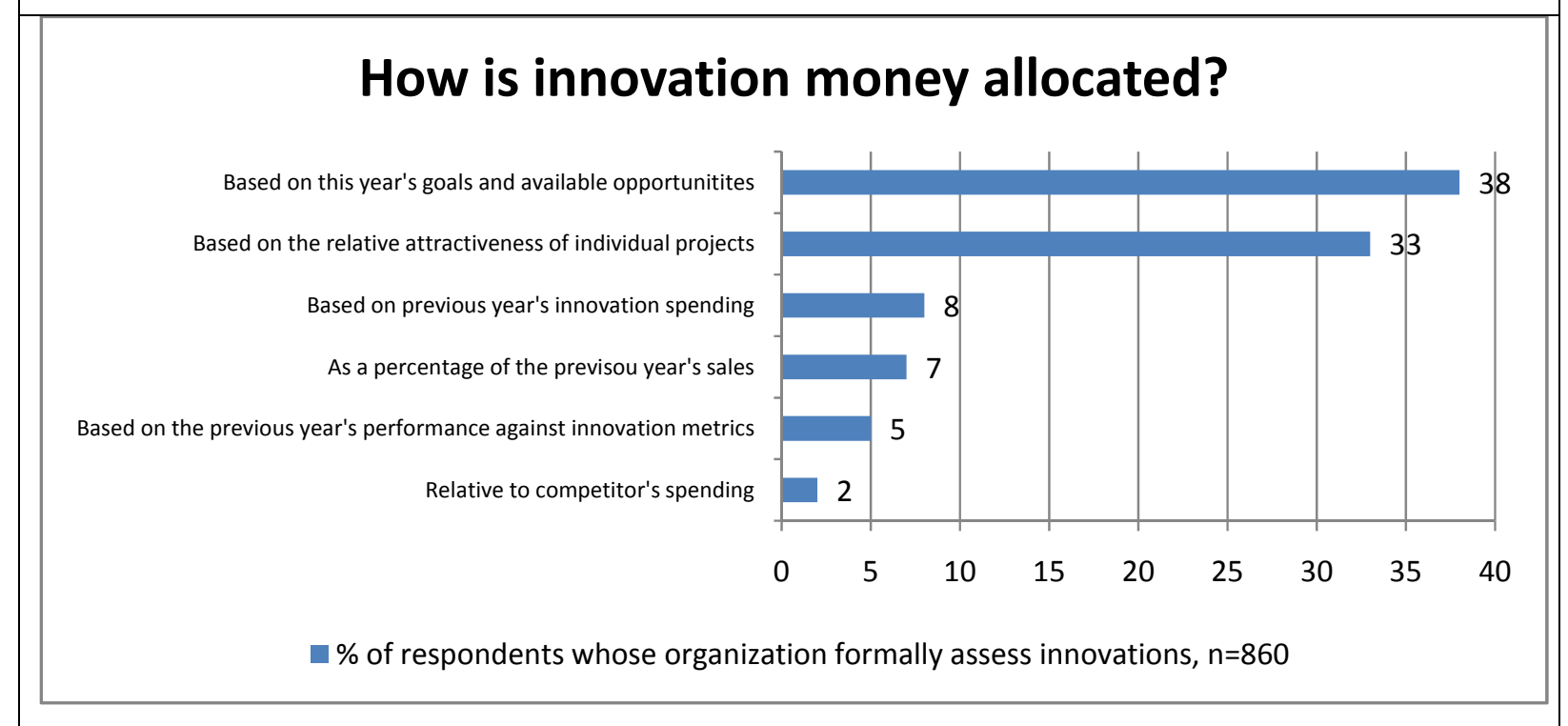

Source: McKinsey 2008 
Arrow (1962) postulated that dominant firms are less innovative because of their inertia to protect the current profit stream. Several studies have developed this view further theoretically (Kamien and Schwartz 1978; Dasgupta, Gilbert and Stiglitz 1983; Reinganum 1983). Schumpeter (1975) on the other hand argued that the incentive to innovate is more than proportionately larger for bigger firms as they have better capability to exploit an innovation. This line of reasoning was extended theoretically to show that dominant firms have more of an incentive to innovate to protect their dominant position from competitors (Gilbert and Newbery 1982; Nault and Vandenbosch 1996, Conner 1998). Recent research shows that whether dominant or less dominant firms innovate first depends on whether firms are myopic, if the investments are strategic substitutes or complements, and if there is free entry into the market (Athey and Schmutzler 2001, Etro 2004). The empirical evidence on this issue is divided: Some researchers have shown that dominant firms are more innovative (Chandy and Tellis 2000) while others have shown that less dominant firms are more innovative (Christensen 1997, Lerner 1997). Moreover, research on the relationship between dominance and innovation is a multifaceted construct where technological expectations can generate differing propensities to innovate among dominant and less dominant firms (Chandy, Prabhu and Antia 2003).

In order to shed more light on this debate, we review how firms allocate resources for innovation. A recent empirical survey on innovation that examined firms' motives for innovation showed that firms allocate resources for innovation mainly based upon the goals set for the year and available opportunities, followed by the relative attractiveness of individual projects (McKinsey 2008). Competitors' spending comes a long way behind at sixth place with only two percent of firms saying that it is important to their decision-making (see Figure 1). However, many analyses of innovation using game theory use the concept of the Nash equilibrium which 
emphasizes the importance of competition. In Nash equilibrium, each firm chooses the action that maximizes their returns subject to the opponent's choice and no firm can gain by changing their strategy unilaterally. By contrast, in this paper we use an alternative concept. We use a decision analytic approach where firms form subjective probabilities over the actions of the firm's opponent and then choose the action that maximizes the firm's expected value ${ }^{3}$. We use the probabilistic choice model developed axiomatically by Luce (1959). We call this the 'returns based beliefs' approach which is both more sympathetic to and more consistent with the results of the innovation survey. Returns-based beliefs bring squarely into the picture the emphasis on the relative attractiveness of individual projects in choosing the optimal level of investments in innovation projects within a competitive setting. In doing so, we also provide an argument for why firms might not be in an equilibrium when choosing their allocation of resources for innovation. Thus, we are able to contribute to the extensive literature on whether dominant firms or less dominant firms innovate more (Chandy and Tellis 2000).

Our expectation might suggest that firms that value an innovation more might invest more in order to gain from the innovation. However, Amaldoss and Jain (2002) show that, in fact, in equilibrium the opposite is true: The firm who has less to benefit from the innovation will invest more aggressively to gain from the innovation. The reason for this result is intimately connected to the very concept of asymmetric mixed strategy equilibrium in games. The concept requires that a firm plays strategies in such a way as to make the opponent indifferent to its strategies. Amaldoss and Jain (2002, pp. 976-977) state this clearly, 'Mixed-strategy solution demands that a firm randomizes its strategies such that the other firm is indifferent to all the

\footnotetext{
${ }^{3}$ Kadane and Larkey (1982) in their seminal paper propose a decision analytic solution concept over the game theoretic solution concept. Rios, Rios and Banks (pp. 845-849, 2009) provide a recent discussion of the difference between game theoretic and decision analytic solution concepts.
} 
strategies in its support'. One of the consequences of this approach to randomization is that a firm or player is dependent on the opponent's returns and not on their own returns from undertaking the innovation. Farrell and Saloner (1988, pp. 250) articulate this clearly in the context of asymmetric mixed strategies in the use of standards, 'For instance, the mixed-strategy equilibrium predicts that the frequency with which a player concedes depends on his opponent's payoffs, not on his own: this is so since his opponent's indifference between strategies must be maintained.' Although the concept of randomization is one interpretation of a mixed strategy, it is not the only interpretation. Later in the paper we shall discuss other interpretations of mixed strategies in the context of uncertainty and subjective probabilities.

However, the results using the randomization interpretation of asymmetric mixed strategy equilibrium contradicts the results from the McKinsey (2008) innovation survey, discussed above. Although Amaldoss and Jain (2004) show that their results hold at the aggregate level, in controlled laboratory experiments there are significant departures from the theoretical predictions at the individual level. Moreover, in early trials the dominant players invested more than the less dominant players and subjects moved towards the equilibrium predictions through learning over several iterations of the game. In this paper, we contend that this result might be the consequence of non-equilibrium behavior displayed by the subjects.

In order to do so, we revisit the use of game theory to analyze competitive settings in which firms operate. Game theory models systematically behavior when strategic interactions exist. In conventional game theory, the solution concept such as Nash equilibrium is critical in forming the basis for the prior distribution of beliefs that firms hold. In determining the outcome of the game these prior beliefs held by the firms are fulfilled in equilibrium. However, a firm's actions are determined by the firm's beliefs about other firms which may depend upon their real- 
life contexts such as the accepted management practice to which the managers of the firm have been accustomed to, and the firm's value systems. The managers' past experience influences the psychological makeup, which in turn affects how the manager perceives their opponent. Game theory typically describes how managers ought to behave rather than how managers should behave given the nature of the game and their experiences (Kadane and Larkey 1982, 1983). Recognizing this weakness, some scholars have argued that what is needed is an empiricallysupported psychological theory that makes probabilistic predictions about strategies firms are likely to use given the nature of the firm and the managers' psychological make-up (Harsanyi, 1982). This psychological makeup might be conditioned by the past experience of managers' beliefs about an opponent's play. This is termed the 'subjective' or personal interpretation of probability. Subjective probability is the probability that a manager assigns to a possible outcome, or some process based on his own judgment, the likelihood that the outcome will be obtained (DeGroot 1975, pp. 4). An implication of the subjective probability approach is that the chosen strategy might not be consistent with the equilibrium predictions of an objectively rational outcome (Roth and Schoumaker 1983b). The firm's experience is an important determinant of the firm's expectations which might lead to strategies being chosen that might not be the Nash equilibrium prediction (Roth and Schoumaker 1983a).

Scholars in earlier decades went so far as to argue that the traditional result of an equilibrium in economics could be overturned (Kaldor 1972, Robinson 1974). For example, the eminent Cambridge economist Joan Robinson argued that 'A model applicable to actual history has to be capable of getting out of equilibrium; indeed, it must normally not be in it' (Robinson, 1962, p. 25). In the corporate world, there are numerous examples of firms choosing to adopt strategies that are not optimal in implementing innovations (Chesbrough and Rosenbloom 2002, 
Kaplan and Henderson 2005). The purpose of this paper is to show the rationale for why firms might choose a non-equilibrium strategy that is ostensibly irrational.

We argue that the rationality of subjective probabilities and what we term 'returns-based beliefs' might explain the adoption of non-equilibrium strategies in game theory, and that this might have wide implications for firms in choosing their innovation strategy. In particular, we show how the use of the returns-based beliefs approach provides support for the thesis that dominant firms invest more in $R \& D$ within an asymmetric mixed strategy game. We argue that the returns-based beliefs approach is more in line with the results of the innovation survey shown in Figure 1. We also provide empirical evidence using UK R\&D data in support of our 'returns based beliefs' approach. By doing so, we provide a new approach to solving games within a nonequilibrium framework which is different from other non-equilibrium models. We also present the implications of our approach for innovation decisions within a competitive setting.

The next section revisits the patent race game between competitive firms. Section 3 discusses our concept of returns-based beliefs. Section 4 compares the returns-based beliefs model with other non-equilibrium models. In section 5 we provide an empirical analysis of R\&D spending. Section 6 discussions the main implications and concludes.

\section{Patent Race between Asymmetric Firms}

In this section we develop a simple model of a patent race. Let us assume that there are two firms, a dominant and less dominant firm, $i=\{\mathrm{H}, \mathrm{L}\}$ respectively. The dominant and less dominant firms are currently earning profits of $e_{H}$ and $e_{L}$ respectively where $e_{H}>e_{L}$. The firms can invest in research and development (R\&D) to win a patent. The maximum amount they can invest is $s \epsilon\left(0, \frac{1}{2} c, c\right)$, where $c$ is the constraint imposed by the capital markets (Amaldoss and 
Jain 2002). Similar to the seminal paper by Gilbert and Newbery (1982), we assume that the firm that invests more wins the patent. If the dominant firm wins the patent it makes a profit of $r_{H}$ and if the less dominant firm wins the patent it makes a profit of $r_{L}$ where $r_{H}>r_{L}\left(r_{H}-e_{H}>r_{L}-\right.$ $\left.e_{L}\right)$. In addition, we assume that (1) $r_{H}-c>e_{H}$, (2) $r_{L}-c>e_{L}$ and $c<r_{L}$. We assume that the dominant firm is able to profit more from the innovation due to the existence of complementary assets such as a better brand name, distribution channels or better marketing ability (Breshnan et al. 1997, Teece 1986). We assume Bertrand competition whereby if both firms invest the same amount in R\&D they earn zero profits. Therefore, firm i's profits if it invests $s_{i}$ are $\pi_{i}=r_{i}-s_{i}$ if $s_{i}>s_{k} ; i \neq k$ or $\pi_{i}=e_{i}-s_{i}$ otherwise. We assume that all profits and costs are common knowledge. The profits with respect to the various levels of investments are shown in Table 1.

\section{Table 1: Payoff matrix for various levels of investment in R\&D}

\begin{tabular}{|c|c|c|c|c|}
\hline \multirow{5}{*}{$\begin{array}{l}\text { Dominant } \\
\text { Firm }\end{array}$} & \multicolumn{4}{|c|}{ Less Dominant Firm } \\
\hline & & 0 & $(1 / 2) c$ & c \\
\hline & 0 & $\left(e_{H}, e_{L}\right)$ & $\left(e_{H}, r_{L}-1 / 2 c\right)$ & $\left(e_{H}, r_{L}-c\right)$ \\
\hline & $(1 / 2) c$ & $\left(r_{H}-1 / 2 c, e_{L}\right)$ & $\left(e_{H}-1 / 2 c, e_{L}-1 / 2 c\right)$ & $\left(e_{H}-1 / 2 c, r_{L}-c\right)$ \\
\hline & c & $\left(r_{H}-c, e_{L}\right)$ & $\left(r_{H}-c, e_{L}-1 / 2 c\right)$ & $\left(e_{H}-c, e_{L}-c\right)$ \\
\hline
\end{tabular}

There is no pure strategy equilibrium for the game (similar to Amaldoss and Jain, 2002). If both firms invest zero than one firm can be better off investing $1 / 2 \mathrm{c}$ and winning the patent. Therefore investing zero is a not a pure strategy equilibrium. If both firms invest a positive amount, then the losing firm is better off by not investing and deviating to zero investment. Therefore, both firms investing a positive amount is not a pure strategy equilibrium either. Now consider the case when one firm does not invest while the other firm invests a positive amount. The firm that invests could win the patent by incurring a cost of $1 / 2 \mathrm{c}$. However, this cannot be an 
equilibrium because the firm that has not invested could win the patent by investing c. Therefore, we do not have a pure strategy equilibrium for this game. The equilibrium must involve a mixed strategy equilibrium whereby each firm invests in the three choices with some probability. Randomization in mixed strategy Nash equilibrium analysis requires that the firms choose their probabilities in such as way as to make the other firm indifferent between the different strategic choices. Let us assume that the dominant firm chooses probabilities $y_{1}, y_{2}, y_{3}$ for investment of $0,1 / 2 c$ and $c$ respectively where $y_{1}+y_{2}+y_{3}=1$. Similarly, the less dominant firm chooses probabilities $x_{1}, x_{2}, x_{3}$ for investment of $0,1 / 2 c$ and $c$ respectively where $x_{1}+x_{2}+x_{3}=1$. For the less dominant firm, equilibrium implies the following:

$$
\begin{aligned}
& e_{H} x_{1}+e_{H} x_{2}+e_{H} x_{3}=\left(r_{H}-\frac{1}{2} c\right) x_{1}+\left(e_{H}-\frac{1}{2} c\right) x_{2}+\left(e_{H}-\frac{1}{2} c\right) x_{3} \\
& e_{H} x_{1}+e_{H} x_{2}+e_{H} x_{3}=\left(r_{H}-c\right) x_{1}+\left(r_{H}-c\right) x_{2}+\left(e_{H}-c\right) x_{3} \\
& x_{1}+x_{2}+x_{3}=1
\end{aligned}
$$

It can be shown from (1), (2) and (3) that

$$
\begin{aligned}
& x_{1}=x_{2}=\frac{c}{2\left(r_{H}-e_{H}\right)} \\
& x_{3}=\frac{r_{H}-e_{H}-c}{r_{H}-e_{H}}
\end{aligned}
$$

Similarly, the dominant firm will choose its mixed strategy equilibrium in such a way as to make the less dominant firm indifferent between its strategic choices. It can be shown that,

$$
y_{1}=y_{2}=\frac{c}{2\left(r_{L}-e_{L}\right)}
$$

$y_{3}=\frac{r_{L}-e_{L}-c}{r_{L}-e_{L}}$

Let us assume that the following holds, $c=2, r_{H}=20, e_{H}=8, r_{L}=10$ and $e_{L}=4$ which gives the payoff as in Table 2 . 


\begin{tabular}{|c|c|c|c|c|}
\hline \multirow{5}{*}{$\begin{array}{l}\text { Dominant } \\
\text { Firm }\end{array}$} & \multicolumn{4}{|c|}{ Less Dominant Firm } \\
\hline & & 0 & $(1 / 2) c=1$ & $c=2$ \\
\hline & 0 & $(8,4)$ & $(8,9)$ & $(8,8)$ \\
\hline & $(1 / 2) c=1$ & $(19,4)$ & $(7,3)$ & $(7,8)$ \\
\hline & $c=2$ & $(18,4)$ & $(18,3)$ & $(6,2)$ \\
\hline
\end{tabular}

Based on (4) to (7), the corresponding equilibrium values for the less dominant firm are as follows:

$x_{1}=x_{2}=0.08$

$x_{3}=0.84$

and for the dominant firm are as follows:

$y_{1}=y_{2}=0.17$

$y_{3}=0.66$

It is clear that the less dominant firm invests more in R\&D compared to the dominant firm (Amaldoss and Jain 2002). To see why this is the case, let us examine the conditions for equilibrium in asymmetric mixed strategy equilibria such as the patent game being examined. The firms have a choice of either investing in $R \& D$ to discover the patent or can choose not to invest. In equilibrium, the firms must be indifferent between these two choices. Let us consider the returns for the dominant firm. The dominant firm has more to gain from winning the patent compared to the less dominant firm because of advantages stemming from complimentary assets and superior marketing advantages. Therefore, the dominant firm needs to invest less and win the patent less often compared to the less dominant firm in order to make it indifferent between 
investing and not investing (see Amaldos and Jain, 2002, p.976). On the other hand, the less dominant firm needs to invest more and win the patent more often to make it indifferent between investing and not investing compared to the dominant firm. Therefore, in the asymmetric mixed strategy equilibrium the less dominant firm invests more in $R \& D$ compared to the dominant firm.

It is clear from the above results (4)-(7), that the mixed strategy equilibrium of the dominant firm, $\mathrm{H}$ does not depend on its own returns from innovation but rather on the less dominant firm's returns, $r_{L}$ and $e_{L}$ (we show a more general case of this result using the mixed strategy Nash equilibrium in Appendix 1). Similarly, the mixed strategy equilibrium of the less dominant firm, L does not depend on its own returns from innovation but rather on the dominant firm's returns, $r_{H}$ and $e_{H}$. However, this seems to contradict the survey in Figure 1 on innovation that shows that firms allocate resources for innovation based on the goals set for the year and available opportunities followed by relative attractiveness of individual projects rather than on the actions of their competitors (McKinsey 2008). In that survey, competitors' spending comes in a mere sixth place with only two percent saying that it is important (see Figure 1). Consequently, we think it important to ask whether it is possible that the mixed strategy equilibrium approach does not capture the essence of the intuition for how firms really make decisions about innovation?

The next section elaborates an alternative approach which combines a decision analytic solution concept and Luce's (1959) probabilistic choice model. This is the returns based beliefs approach which is more in line with the results of the survey and does indeed provide outcomes that are different to the mixed strategy equilibrium approach, adding to the debate about whether dominant or less dominant firms are more apt at innovation. 


\section{Returns-Based Beliefs and Innovation}

In the following discussion, we assume that firms are expected profit maximizers. We argue that, driven by the desire to want to avoid either both firms investing or both firms not investing in $R \& D$ in the patent race game in order to maximize expected profits, there is 'strategic uncertainty' regarding the conjecture about the choice of the other firm. We define strategic uncertainty as uncertainty that concerns the actions and beliefs (and beliefs about the beliefs) of others (Brandenburger 1996). Researchers have argued that strategic uncertainty can arise even in cases when all possible actions and returns are completely specified and are common knowledge (Van Huyck 1990). In such a situation, the rational firm has to form beliefs about the strategy that the other firm will adopt as a result of strategic uncertainty. As a consequence, firms form their beliefs about the probabilities that other firms play in order to determine in turn their best-response strategy. Hence, the best response strategy of one firm is likely to be based upon the mixed strategy of the other firm. The mixture is a result of the uncertainty regarding the conjecture about the choice by the other firms ${ }^{4}$ (Brandenburger and Dekel 1987). This notion has been summarized as follows: 'In psychological games, there can be a difference between interpreting mixed strategies literally as purposeful mixing by a player versus interpreting them as uncertainty by other players' (Rabin 1993, p.1286).

\footnotetext{
${ }^{4}$ We are not assuming that the opponent is using a randomized strategy. The mixture merely reflects the representation of the dominant firm's belief about the less dominant firm, and vice versa. As Wilson (1986, p.47) points out, although it makes little difference to the mathematics, conceptually this distinction between randomization and subjective beliefs to explain the mixed strategies is an important one to consider. This interpretation is also in line with Harsanyi's (1973) purification interpretation of mixed strategy where mixing represents uncertainty in a player's mind about how other players will choose their strategies, rather than deliberate randomization (Morris 2008).
} 
As discussed earlier, when randomized mixed strategies are used a firm chooses probabilities (over their own strategies) in such a manner as to make the other firm indifferent between the different strategies. The implication of this is that each firm's equilibrium strategy depends only on the other firms' payoff and not their own. This randomized mixed strategy approach to choosing the probabilities of the focal firm makes the other firm indifferent between the different strategies (Janssen 2008). However, this approach of randomized mixed strategy would not be appropriate in the case when non-equilibrium strategies are chosen via the use of subjective probabilities. This is because when such non-equilibrium outcomes are chosen, each firm maximizes their own expected values based on their conjecture of what the opponent is likely to do. Therefore, the probabilities are chosen by the focal firm over their strategies based on their conjecture of what the other firm is likely to do. Hence due to strategic uncertainty regarding the conjecture about the choice of the other firm, the focal firm holds an opinion based on the subjective probability with respect to all of the unknown contingencies affecting its payoffs. In particular the firm is assumed to have a view about the major contingency faced, namely what the opposing firm is likely to do (Kadane and Larkey 1982, p. 115). Kadane and Larkey (1982, p. 115) expressed the implications of this line of thinking very neatly as follows: 'If I think my opponent will choose strategy $i(i=1, \ldots I)$ with probability $p_{i}, I$ will choose any strategy $j$ maximizing $\sum_{i=1}^{I} p_{i} u_{i j}$, where $u_{i j}$, is the utility to me of the situation in which my opponent has chosen i and I have chosen j......the opponent's utilities are important only in that they affect my views $\left\{p_{i}\right\}$ of what my opponent may do....'.

Therefore, it follows that if firm 2 is not expected to play the mixed strategy Nash equilibrium then it might be optimal for firm 1 also not to play the mixed strategy Nash equilibrium. This is because doing so would give firm 1 a better payoff as firm 1 has a profitable 
deviation from not playing the mixed strategy Nash equilibrium when the other firm also does not play the mixed strategy Nash equilibrium. The implication of this is that the Nash equilibrium is a special case when each firm is assumed to believe that the other is sure to play the Nash equilibrium strategy. The concept of objective and subjective probabilities helps to make clear the context of this discussion: the Nash equilibrium solution concept assumes rationality from the perspective of an external observer which in effect implies objective probabilities. However, at the level of the individual firm, assumptions about the opponent's beliefs may be conditioned by the accepted management practice and value systems of the firm and hence might be different from the priors held by the rational external observer. Therefore, a focal firm who knows that the non-Nash equilibrium belief is held by the other firm could be deemed to be rational when forming a subjective assessment of the other firm's action by taking this belief into account (Basu 1990). In situations of strategic interaction such as the patent race game, the firms might hold subjective probabilities that are different from the objective probabilities demanded by the Nash equilibrium solution concept. When the subjective and objective probabilities are the same we get the special case of the Nash equilibrium. However, there is no compelling reason a priori for the subjective and objective probabilities to definitely be the same. Although any distribution of probabilities could be possible based upon the subjective method of forming them, we shall try to propose a reasonable subjective probability belief that the firms might use when they do not know each other's respective histories. We call this 'returns-based beliefs'.

We posit that the firms have a desire to want to cooperate in order to achieve an outcome whereby one firm invests while the other stays out. However, the rational firm has to form beliefs about the opponent's strategies due to the strategic uncertainty about what the opponent is 
likely to invest. Following Luce (1959) probabilistic choice model, we assume that firms form beliefs based upon the expected returns for a particular strategy over the total expected returns of all strategies. Therefore, it is reasonable to assume that the firm would assign probabilities based on the expected returns from playing the different strategies. Similarly, we assume that the other firm also assigns probabilities based on the other firm's expected returns given the probabilities of the focal firm. Following this logic, our analysis is based on a model for which the decision probabilities are proportional to the expected returns. Our proposed approach has both theoretical and empirical support. First, for the theoretical merit we defer to Luce (1959) who showed using probability axioms that if the ratio of probabilities associated with any two decisions is independent of the payoff of any other decisions, then the choice probabilities for decision $i$ can be expressed as a ratio of the expected payoff for that decision over the total expected payoff for all decisions: $\frac{\Pi_{i}^{e}}{\sum_{j} \Pi_{\mathrm{j}}^{\mathrm{e}}}$ where $\Pi_{j}^{e}$ is the expected returns associated with decision i. Second, this method of arriving at decision probabilities has been justified by empirical work which provides empirical support for our approach. In particular, empirical research for paired comparison data provides support for the Luce (1959) method of arriving at decision probabilities such that the probability for choosing $x$ over $y, P(x, y)=\frac{v(x)}{[v(x)+v(y)]}$ where $v(x)$ and $v(y)$ are the scale values of choosing $x$ and $y$ respectively (Abelson and Bradley 1954). Our model has similarities with the logit equilibrium version of the quantal response equilibrium model (QRE) proposed by McKelvey and Palfrey (1995) and the bounded rationality Nash equilibrium (BRNE) model of Chen, Friedman and Thisse (1997) in that all strategies with positive payoffs are played with positive probabilities in proportion to their expected payoffs. Although there are similarities, our reasoning for the decision making process is very different to other models. Moreover, our model is more parsimonious as it does not require the specification of an error term. We discuss these 
points further below in the section on comparing the returns based belief model to other nonequilibrium models. We operationalize our model as follows. In this model, each firm chooses among $\mathrm{n}=3\left(s_{i}=0, \frac{1}{2} c, c\right)$ possible strategies and the expected payoffs are given by the summation below:

$$
\pi_{i}^{e}(s)=\sum_{m=1}^{n} \pi_{i}(s, m) p_{i}(m) \quad\left(s_{i}=0, \frac{1}{2} c, c\right)
$$

where $\pi_{i}(s, m)$ is firm $i$ 's payoff from investing $s_{i}$ when the other firm invests $m$ and $p_{i}(m)$ is the belief probabilities held by firm $i$ about the other firm playing strategy $m$. In turn, the decision probabilities follow the specification outlined above which is proportional to the expected returns as follows:

$$
D_{i}(s)=\frac{\pi_{i}^{e}(s)}{\sum_{m=1}^{n} \pi_{i}^{e}(m)}
$$

In our model we assume a Nash-like equilibrium in belief formation such that the belief probabilities match the decision probabilities for both the dominant firm and the less dominant firm respectively. This symmetry between these belief probabilities is achieved by iterating between the expected payoff in equation (8) and the decision probabilities in equation (9). The idea is that firm $i$ computes the expected payoff, $\Pi^{\mathrm{i}}\left(\mathrm{s}_{\mathrm{i}}, \sigma_{\mathrm{M}}\right)$ of each pure action $s_{i}$ given a mixed action $\sigma_{\mathrm{M}}$ of the other firm. Firm $i$ would play the mixed action, 


$$
\sigma_{\mathrm{i}}\left(\mathrm{s}_{\mathrm{i}}\right)=\frac{\Pi^{\mathrm{i}}\left(\mathrm{s}_{\mathrm{i}}, \sigma_{\mathrm{M}}\right)}{\Pi^{\mathrm{i}}\left(\mathrm{C}, \sigma_{\mathrm{M}}\right)+\Pi^{\mathrm{i}}\left(\mathrm{D}, \sigma_{\mathrm{M}}\right)}, \quad\left(s_{i}=0, \frac{1}{2} c, c\right)(10)
$$

If firm $i$ knew that the opponent played $\sigma_{\mathrm{M}}$. This defines the mapping from $j$ 's mixed action to $i$ mixed actions. The firm then plays a fixed point of this mapping. Therefore, we have the following proposition:

PROPOSITION 1. A game $(i, s, \pi)$ has a returns based belief equilibrium.

McKelvey and Palfrey (1995) show that there exists such a fixed point equilibrium ${ }^{5}$. Hence the equilibrium can be thought of as a set of consistency conditions whereby a firm's choice probabilities are correct in the sense of reflecting what the firm must do when the choice probabilities are best replies to the strategies of the other firm which forms such subjective choice probabilities in proportion to the expected returns of the strategies ${ }^{6}$. A more general set up of the returns based belief approach is shown in Appendix 2. It is not possible to find an analytical solution to the returns based belief probabilities when we have the three strategies as in our example ${ }^{7}$. Therefore we have to apply numerical methods to find the solution (Werner and

\footnotetext{
${ }^{5}$ In the McKelvey and Palfrey (1995) logit equilibrium (where the errors have a log Weibull distribution) version of the quantal response equilibrium model, they show the existence of such fixed point equilibrium when their error parameter goes from $\mu=0$ to $\mu=\infty$. Chen, Friedman and Thisse (1997) provide a general set up of the logit equilibrium model and note that all McKelvey and Palfrey (1995) results for the existence of equilibrium will carry through. Although the basis of our model is very different, our model relates to the Chen, Friedman and Thisse (1997) model when no such error parameter is needed or when $\mu=1$.

${ }^{6}$ This is similar to Binmore's (2009, p.135) 'subjective probabilities whereby beliefs rather than strategies are treated as primary'. Camerer (pp. 150, 2003) makes a similar point that mixed strategy equilibrium can be seen as an equilibrium in beliefs. The returns based beliefs approach is different from Nash equilibrium because players are not playing best responses given their beliefs, but placing probability on strategies in proportion to their expected payoff.

${ }^{7}$ Selten and Chmura (2008, p. 941) make a similar point for a completely mixed $2 \times 2$ game with respect to the quantal response equilibrium. In that case, the equilibrium cannot be described by explicit formulas and hence they need to be calculated numerically.
} 
Sotskov 2006, p.369). We demonstrate the existence of such a fixed point equilibrium through the numerical example below.

To begin the analysis, let us assume that the dominant firm believes that the less dominant firm plays each of the strategies with equal probabilities i.e. 0.33 . We then multiply 0.33 with the rewards of the dominant firm (as per Table 2) to get the expected returns as shown in Table 3. For example, the number 2.67 (row one and column one in Table 3) is obtained by multiplying 0.33 by 8 (the first number in parentheses in row one and column one in Table 2). The second last column labeled 'Total' shows the total rewards for a particular claim for the dominant firm for all possible claims by the less dominant firm. For example, 8.00 is the sum of all the rewards $(2.67+2.67+2.67)$ for the 'do not invest' strategy by the dominant firm when the less dominant firm plays do not invest, invest $1 / 2 \mathrm{c}$ or $\mathrm{c}$ with equal probabilities i.e. 0.33 .

We now need to calculate the probabilities that the dominant firm will invest in the different amounts of possible $R \& D$ investment levels. As discussed above, the dominant firm is concerned about the less dominant firm's returns only to the extent that the dominant firm wants to maximize its own return subject to the less dominant firm's strategy. Therefore, it might be reasonable to assume that the dominant firm assigns probabilities to each of the investment levels proportionally to the expected returns of playing that strategy. The last column in Table 3 depicts the probabilities that the dominant firm would play a particular strategy in response to the various investment levels for the less dominant firm. This is derived by dividing the reward the dominant firm gets for a particular investment level by the total rewards for all possible investment levels of the dominant firm. For example, the number in the last column and first row of Table 3, 0.24 is obtained by dividing 8.00 (the number in the first row of the column labeled 
'Total' in Table 3 ) by the total of 33.00 (the number in the far right row in the column labeled 'Total' in Table 3).

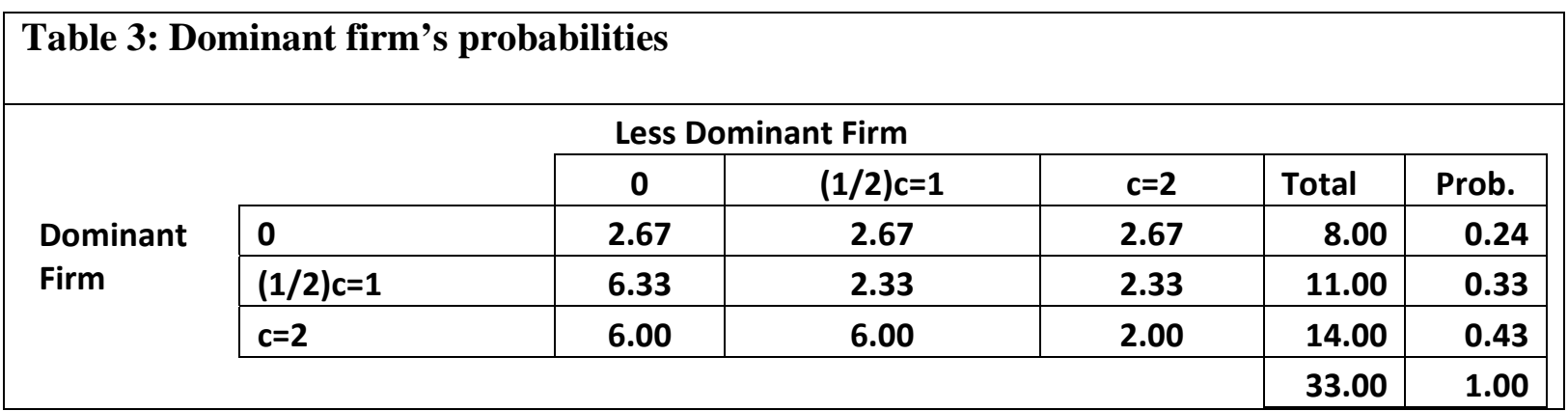

Now in turn, the less dominant firm's expected returns can be calculated by applying the probabilities that the dominant firm will invest as calculated from Table 3 above. In a similar way, the dominant firm's revised probabilities for each of the investment levels can be calculated based on the returns based beliefs method described for the dominant firm above. We now revise the expected returns in Table 3 with the new probabilities (as compared to the equal probabilities that we started out with). This process provides updated probabilities for the less dominant firm for each investment level, as shown by the revised numbers in the last row of Table 3. This process can be repeated until the probabilities for the dominant and less dominant firm stabilize. Conducting this iterative process shows that these probabilities do actually stabilize after about three to four iterations ${ }^{8}$.

The probabilities converge as follows for the dominant firm,

$y_{1}=0.25$

\footnotetext{
${ }^{8}$ Since the firms are asymmetric, it is not unreasonable to assume without any further information about accepted management practices or value systems that they would have different subjective beliefs about each other.
} 
$y_{2}=0.33$

$y_{3}=0.42$

and as follows for the less dominant firm,

$x_{1}=0.29$

$x_{1}=0.32$

$x_{3}=0.39$

Under the returns based belief approach, given the returns profile, the dominant firm will invest more than the less dominant firm in R\&D. Therefore, we have the following result:

RESULT 1. On average Firm H invests more than Firm L in the returns based beliefs approach.

This is consistent with the empirical evidence provided by the McKinsey (2008) survey on innovation spending (see Figure 1). Moreover, the value of the mixed strategy Nash equilibrium for the dominant firm and the less dominant firm are 8.0 and 4.0 respectively. In contrast, the expected value under the returns based beliefs approach for the dominant firm and the less dominant firm are higher at 11.0 and 4.7 respectively. Therefore, as discussed earlier, the dominant firm and the less dominant firm have profitable deviations from not playing the mixed strategy Nash equilibrium, when the other firms does not play the mixed strategy Nash equilibrium. 


\begin{tabular}{|c|c|c|c|c|c|c|}
\hline & & & \multicolumn{2}{|c|}{$\begin{array}{l}\text { Change in } \\
\text { returns for } \\
\text { dominant firm by } \\
+10\end{array}$} & \multicolumn{2}{|c|}{$\begin{array}{l}\text { Change in returns } \\
\text { for the less } \\
\text { dominant firm by } \\
+4\end{array}$} \\
\hline & & & Nash & $\begin{array}{l}\text { Returns } \\
\text { based } \\
\text { belief }\end{array}$ & Nash & $\begin{array}{l}\text { Returns } \\
\text { based } \\
\text { belief }\end{array}$ \\
\hline \multirow[b]{3}{*}{ Dominant Fim } & No investment & $\mathrm{y} 1$ & 0 & -0.06 & -0.07 & 0.01 \\
\hline & $\begin{array}{l}\text { Investment of } \\
(1 / 2) c\end{array}$ & $y^{2}$ & 0 & 0 & -0.07 & -0.01 \\
\hline & Investment of c & $y^{3}$ & 0 & 0.06 & 0.14 & 0 \\
\hline \multirow{3}{*}{$\begin{array}{l}\text { Less Dominant } \\
\text { Firm }\end{array}$} & No investment & $\mathrm{x} 1$ & -0.04 & 0.01 & 0 & -0.06 \\
\hline & $\begin{array}{l}\text { Investment of } \\
(1 / 2) c\end{array}$ & $x 2$ & -0.04 & -0.01 & 0 & 0 \\
\hline & Investment of c & $x 3$ & 0.08 & 0 & 0 & 0.06 \\
\hline
\end{tabular}

Table 4 provides the sensitivity of the probabilities to changes in returns from the patent for both the dominant and less dominant firms. We provide two sensitivity analyses. The first is when the returns for the dominant firm from the innovation, $r_{H}$ increases by 10 from 20 to 30 . For the Nash equilibrium, the sensitivity analysis shows that the dominant firm's probabilities do not change while the less dominant firm invests more in $R \& D$ as the probability of investment of c, increases by 0.08 percent. In the case of the returns based belief approach the dominant firm increases its investment in $R \& D$ as the probability of investment of c, increases by 0.06 percent. The impact on the less dominant firm is marginal. The second analysis is when the returns for the less dominant firm from the innovation, $r_{L}$ increases by 4 from 10 to 14 . For the Nash equilibrium, the sensitivity analysis shows that the less dominant firm's probabilities do not change while the dominant firm invests more in $R \& D$ as the probability of investment of $c$, 
increases by 0.14 percent. In the case of the returns based belief approach the less dominant firm increases its investment in $R \& D$ as the probability of investment of $c$, increases by 0.06 percent. The impact on the dominant firm is marginal. Therefore, we have the following result:

RESULT 2. Firm H (Firm L) investment depends more on its own returns, $r_{H}\left(r_{L}\right)$ than the other firm's returns $r_{L}\left(r_{H}\right)$.

These results are more in line with the McKinsey (2008) survey on innovation spending which highlights that the primary driver for innovation spending is opportunities and the relative attractiveness of the innovation, consequently with a much lower emphasis on the competitor's spending (as shown in Figure 1).

\section{Empirical Analysis of the Determinants of R\&D Investments}

Our empirical analysis consists of testing whether the mixed strategy Nash equilibrium or the returns based beliefs approach provides a better explanation for how firms determine their R\&D spending. Recall that under the mixed strategy Nash equilibrium firms would change their R\&D spending based on the R\&D spending of their competitors. On the other hand, the McKinsey survey (2008) on innovation spending showed that R\&D spending of firms are driven less by the competitors' spending, but more by the available opportunities and the attractiveness of individual projects. Our proposed returns based beliefs approach provides a closer theoretical explanation for the result of the McKinsey (2008) survey than the mixed strategy Nash equilibrium. However, in order to test the validity of these two approaches we performed an empirical analysis based on R\&D spending of 182 UK companies across 24 industry sectors. 
We obtained data from the UK R\&D scoreboard between 2001-2006 which is published jointly by the Department for Innovation, Universities \& Skills (DIUS) and the Department for Business, Enterprise \& Regulatory Reform (BERR). The dependent variable of interest is the annual percentage change in $R \& D$ over sales. To operationalize the competitor's $R \& D$ spending we used the annual change in industry $R \& D$ spending excluding the individual firm's own $R \& D$ spending. To operationalize available opportunities and the attractiveness of the individual projects we constructed a measure that captures the annual change in the difference between the industry return on sales (the industry's total operating profits for the year over the industry's total sales for the year), less the firm level return on sales (an individual firm's operating profit for the year over its sales for the year). This excess return on sales measure provides a proxy for the opportunities that the firm has to innovate its products and processes to be in line with the level of profitability of other firms in its industry. When the measure is positive, there are more opportunities to innovate to catch up with the other firms in its industry compared to when the measure is negative. For our model specifications, we use a random effects model and estimate the parameters while controlling for the size of the firm (by using the logarithm of the number of employees) and industry. The results of the regression analysis are shown in Table 5. 


\begin{tabular}{|lc|}
\hline \multicolumn{2}{|c|}{ Table 5: Determinants of R\&D Investments } \\
\hline \multicolumn{1}{|c|}{ Dependent Variable: Percentage change in R\&D over sales } \\
\hline Industry R\&D & $0.025(0.016)$ \\
Excess return on sales & $0.024^{*}(0.004)$ \\
Employee size & $-9.066^{*}(1.670)$ \\
Year & $1.352 \quad(1.144)$ \\
Industry & $0.744(0.054)$ \\
Intercept & $-2642.651(2293.515)$ \\
\hline No of observations $=1092$ \\
p-value, chi squared test $=0.000$ \\
$\mathrm{R}^{2}=0.21$
\end{tabular}

${ }^{*} \mathrm{p}<0.01$ (Note: Standard errors in parentheses)

We find a significant positive relationship between the change in $R \& D$ over sales for an individual firm and the opportunities and the attractiveness of the individual projects. $(\beta=$ 0.024, $p<0.01$ ). On the other hand, there is no significant relationship between change in R\&D over sales for an individual firm and the competitors' $R \& D$ spending. The empirical analysis provides support for the returns based beliefs approach compared to the theoretical predictions of the mixed strategy Nash equilibrium for the patent raced based innovation game. In the next section we compare the returns based beliefs approach to other non-equilibrium models. 


\section{Comparing Returns-Based Beliefs to Alternative Non-Equilibrium Models}

In this section, we compare our model based upon returns-based beliefs to several alternative models that also explain non-equilibrium outcomes. The three models that are relevant include the quantal response equilibrium or QRE (McKelvey and Palfrey 1995), the cognitive hierarchy model or CH (Camerer, Ho and Chong 2004) and level-k models (Costa-Gomes and Crawford 2006) which all have their foundations on cognitive limitations. The QRE can be interpreted as an application of stochastic choice theory to strategic games or as a generalization of the Nash equilibrium that incorporates noisy optimization (Haile, Hortacsu and Kosenok 2008). The QRE assumes that the decision maker might take an action that is suboptimal, and that the probability of doing so increases with the expected payoff of that action. In this model, the decision maker adopts strategies proportional to the expected payoff with some error. The error the decision maker makes could be seen as either unmodeled costs of information processing (McKelvey and Palfrey 1995) or unmodeled determinants of utility from any particular strategy (Chen, Friedman and Thisse 1997). The use of QRE and the boundedly rational Nash equilibrium (BRNE) of Chen et al (1997) requires the specification of an error distribution. Many applications in the literature of such QRE models assume logit choice probabilities. It has been shown that the QRE and the BRNE models' prediction converge to the Nash equilibrium as the error goes to zero for a logit specification. Our model's main similarity to the QRE and the BRNE model is that all strategies with positive payoffs are played with positive probabilities in proportion to their expected payoffs. However, our model differ quite radically from the QRE and the BRNE models in an important respect in that our model does not require the specification of an error distribution and therefore is more parsimonious. In addition we invoke the concept of subjective 
probabilities and the willingness of firms to cooperate which differs inherently from the unmodeled costs of information processing (McKelvey and Palfrey 1995) or unmodeled determinants of utility from any particular strategy (Chen, Friedman and Thisse 1997).

The level-k and cognitive hierarchy $(\mathrm{CH})$ models explain the payoff-sensitivity of the deviations from equilibrium by incorporating them within the structure of the game as opposed to responses to errors. The level-k and $\mathrm{CH}$ models allow heterogeneous behavior in that the levels of sophistication of the decision makers can vary across the decision makers. Some decision makers are very simplistic and non-strategic. On the other hand, others are more sophisticated and best respond to the distribution of less sophisticated decision makers. The nonequilibrium outcome of the game is determined by the level of sophistication of the decision makers and the proportion of decision makers at each level of sophistication. The level-k and $\mathrm{CH}$ models differ principally in their assumptions about how the more sophisticated decision makers respond to decision makers with sophistication levels below them. In the case of the level-k model, the more sophisticated decision maker respond only to decision makers with one level of sophistication below them. In contrast, in the $\mathrm{CH}$ model the more sophisticated decision makers respond to the distribution of decision makers at all levels of sophistication below them. The returns-based model differs from the level-k and the $\mathrm{CH}$ models in that the former does not assume heterogeneity in the levels of sophistication in thinking by decision makers. On the other hand, the returns-based model assumes symmetry in the ability of decision makers to iterate strategically until the belief probabilities converge to the decision probabilities. 


\section{Conclusion and Managerial Implications}

The debate about whether dominant firms or less dominant firms are more innovative is at the heart of research on innovation. Both the theoretical and empirical research on this question is still subject to great debate. Research has shown that within an asymmetric mixed strategy game of a patent race, the less dominant firm invests more in innovation and wins the patent more often (Amaldoss and Jain 2002). Although, Amaldoss and Jain (2002) show that their results hold at the aggregate level in controlled laboratory experiments, there are significant departures from the theoretical predictions at the individual level. Moreover, in the early trials the dominant players invested more than the less dominant players and subjects moved towards the equilibrium predictions through learning over several iterations of the game. The asymmetric mixed strategy game uses the concept of the Nash equilibrium that shows that the strategies of the firms are dependent not on their own returns but upon the returns of the opponent from innovating. The paper provides an explanation for why dominant firms fail to innovate - market advantage might encourage aggressive investment by less advantageous firms which in turn might impede innovation by the dominant firms that enjoy the market advantage. Although theoretically plausible, the result does not support the findings from the innovation survey as shown in Figure 1 (McKinsey 2008).

In this paper we argue that it is important not only to understand the possible Nash solutions in formulating strategy (which frequently act as benchmarks) but equally that it is also of fundamental importance to understand the expected relative returns that could potentially influence decisions that concern strategic choice in innovation. Our approach which we call the 'returns based beliefs' approach is based on a combination of decision analytic solution concepts 
and Luce's (1959) probabilistic choice model. The 'returns based beliefs' approach provides support for the counter argument that explains why dominant firms might innovate more market advantage might induce the dominant firm to invest more although competition might encourage the less dominant firm to invest, this competitive effect might not be large enough to overcome the dominant firm's incentive to leverage its market advantage. Our approach is more in line with the innovation survey and general observations on how firms allocate their innovation spending. We also provide empirical evidence using UK R\&D data which provides support for the 'returns based beliefs' approach. The returns based beliefs approach starts with the premise that firms might form subjective probabilities and hence could generate results that are out of equilibrium. The economist Nicholas Kaldor had argued that the prevalence of increasing returns for example from productivity improvements implies that change becomes progressive and propagates itself (Kaldor 1972, pp 1244). In such a system the economy could become out of equilibrium perpetually. One of the managerial implications of this view is that it is important to understand when a market could be out of equilibrium. Based on this line of reasoning it could be argued that industries that display continuous productivity improvements operate out of equilibrium and hence in these contexts an approach such as the 'returns based beliefs' might be more appropriate than the Nash equilibrium concept. Moreover, in such industries the past experience of managers could inform the formation of subjective probabilities. The knowledge and experience of the organization could affect the innovation strategy as the cognitive frames could impede innovation (Chesbrough and Rosenbloom 2002, Kaplan and Henderson 2005). For example, it has been argued in other research that Xerox did not commercialize many of its inventions from its research lab PARC, because the new business model that was required to commercialize these inventions did not conform to the historical 
business model of Xerox (Chesbrough and Rosenbloom 2002). Therefore, the relative profitability of these innovations is what drove the investment of innovation dollars more than the desire to keep competitors indifferent to their different strategies. Finally, it is important for firms to understand how competitors might allocate resources for innovation based upon the relative attractiveness of the competitor's own opportunities rather than based upon any notion of the other firms' opportunities. Thus, the empirical study of innovation could be supported by more relevant theory, such as the returns-based beliefs approach, that establishes more accurately the theoretical underpinnings for the links between a firm's dominance and its likelihood of undertaking innovation in the market. 


\section{Appendix 1}

Let us assume there are two firms, firm 1 (dominant) and firm 2 (less dominant), and that the payoffs for firm 1 and firm 2, given move $i$ for firm 1 and move $j$ for firm 2 are $\Pi_{i j}^{1}$ and $\Pi_{i j}^{2}$ respectively. We assume that there are no pure strategy equilibrium of this game and hence both firms play a mixed strategy, which we denote by $\mathrm{P}^{1}$ for firm 1 and $\mathrm{P}^{2}$ for player $2 . \mathrm{P}^{1}$ is a vector with components $\left\{p_{i}^{1}\right\}$ which are the probabilities that firm 1 will play move $i$, and similarly for firm 2. The expected payoffs for players 1 and 2, which we denote by $E_{1}$ and $E_{2}$ are then

$E_{1}=\sum_{i j} \Pi_{i j}^{1} p_{i}^{1} p_{j}^{2}$

$E_{2}=\sum_{i j} \Pi_{i j}^{2} p_{i}^{1} p_{j}^{2}$

In a Nash equilibrium, no firm can improve their expected return by varying their own strategy while their opponents keep their strategies fixed. Mathematically, this means that the Nash equilibrium is a turning point of $E_{1}$ with respect to variations in the $p_{i}^{1 \prime} s$ only, subject to the constraint that the $p_{i}^{1 \prime} s$ represent a probability distribution, i.e., $\sum_{i} p_{i}^{1}=1$, and it is a simultaneous turning point of $E_{2}$ with respect to variations in the $p_{i}^{2 \prime} s$ only, with the constraint, $\sum_{i} p_{i}^{2}=1$. Maximization subject to the constraints is achieved using Lagrange multipliers, i.e., we extremize the function,

$\sum_{i j} \Pi_{i j}^{1} p_{i}^{1} p_{j}^{2}-\lambda \sum_{i} p_{i}^{1}$

with respect to the $p_{i}^{1 \prime} s$ and extremise the function 
$\sum_{i j} \Pi_{i j}^{2} p_{i}^{1} p_{j}^{2}-\mu \sum_{i} p_{i}^{2}$

with respect to the $p_{i}^{2 \prime} s$. Differentiation of these two equations with respect to the relevant variables yields the equations

$\sum_{i j} \Pi_{i j}^{1} p_{j}^{2}-\lambda=0 \quad \forall i$

$\sum_{i k} \Pi_{i k}^{2} p_{k}^{1}-\mu=0 \quad \forall j \quad(6 \mathrm{~A})$

We can eliminate the Lagrange multipliers $\lambda$ and $\mu$ using the probability condition

$\sum_{i} p_{i}^{1}=\sum_{i} p_{i}^{2}=1$ to deduce

$p_{i}^{1}=\frac{\sum_{j}\left(\Pi^{2}\right)_{j i}^{-1}}{\sum_{i j}\left(\Pi^{2}\right)_{i j}^{-1}}$

$p_{i}^{2}=\frac{\sum_{j}\left(\Pi^{1}\right)_{j i}^{-1}}{\sum_{i j}\left(\Pi^{1}\right)_{i j}^{-1}}$

We can see from results $(7 \mathrm{~A})$ and $(8 \mathrm{~A})$ that the mixed strategy Nash equilibrium for firms 1 and 2 respectively depends on the returns of the other firm's profits and not its own profits.

\section{Appendix 2}

For the returns based beliefs we shall use the same notations for the two firms' returns and probabilities as in Appendix 1. The equilibrium conditions re-defined by the equations,

$p_{i}^{1}=\alpha \Pi_{\mathrm{ij}}^{1} p_{\mathrm{j}}^{2}$

$p_{i}^{2}=\beta \Pi_{\mathrm{ij}}^{2} p_{\mathrm{i}}^{1}$

We use $\alpha$ and $\beta$ to represent the normalization conditions where,

$\alpha=\frac{1}{\sum_{i} \Pi_{\mathrm{ij}}^{1} p_{\mathrm{j}}^{2}}$ 
$\beta=\frac{1}{\sum_{j} \Pi_{\mathrm{ij}}^{2} p_{\mathrm{i}}^{1}}$

The equations now resemble eigenvalue equations for matrices as follows,

$\mathrm{P}^{1}=\alpha U^{1} \cdot \mathrm{P}^{2}$

$\mathrm{P}^{2}=\beta U^{2^{T}} \mathrm{P}^{1}$

which can be rearranged to give

$\mathrm{P}^{1}=\alpha \beta U^{1} \cdot U^{2^{T}} \cdot \mathrm{P}^{1} \quad \Rightarrow \quad U^{1} \cdot U^{2^{T}} \cdot \mathrm{P}^{1}=v \mathrm{P}^{1}$

$\mathrm{P}^{2}=\alpha \beta U^{2^{T}} \cdot U^{1} \cdot \mathrm{P}^{2} \quad \Rightarrow \quad U^{2^{T}} \cdot U^{1} \cdot \mathrm{P}^{2}=v \mathrm{P}^{2}$

where $v=\frac{1}{(\alpha \beta)}$

We deduce that in the returns based beliefs equilibria $\mathrm{P}^{1}$ is an eigenvector of $U^{1} \cdot U^{2^{T}}$ and $\mathrm{P}^{2}$ is an eigenvector of $U^{2^{T}} \cdot U^{1}$, with the eigenvalue equal to $v$ in both cases. The value of the eigenvalue is unimportant in this case, since it is just the normalisation constant. In general there are $\mathrm{N}$ eigenvectors for a N-dimensional matrix, and therefore there could be multiple returns based beliefs equilibria. In the case of our example where $\mathrm{N}=3$, there are three equilibria. However, two of them are complex number solutions and can be ruled out. The only valid equilibria is the one calculated using the numerical iteration procedure (as discussed in Section 3). In practice the numerical iteration procedure closely replicates the thinking process and hence is an appropriate method to find the feasible returns based belief probabilities. 


\section{References}

Abelson, R. M., Bradley, R. A. 1954. A2 X A2 factorial with paired comparisons. Biometrics. 10

(4) 487-502.

Amaldoss, W., Jain, S. 2002. David vs. Goliath: An analysis of asymmetric mixed-strategy games and experimental evidence. Management Science 48 (8) 972-991.

Arrow, K.J. 1962. Economic Welfare Allocation of Resources for Invention, in R. Nelson, ed., The Rate and Direction of Inventive Activity: Economic and Social Factors. Princeton University Press. Princeton, N.J.

Athey, S., Schmutzler, A. 2001. Investment and Market Dominance. Rand Journal of Economics. 32 (1) 1-26.

Basu, K. 1990. On the non-existence of a rationality definition for extensive games. International Journal of Game Theory. 19 (1) 33-44.

Binmore, K. 2009. Rational Decisions. Princeton University Press.

Brandenburger, A. 1996. in Wise Choices, eds Zeckhauser. R. J., Keeney. R. L., Sebenius. J. K. Harvard Business School Press. Boston, MA.

Brandenburger, A. and Dekel, E. 1987. Rationalizability and correlated equilibrium. Econometrica. 55 (6) 1391-1402.

Camerer, C F. 2003. Behavioral Game Theory: Experiments in Strategic Interactions. Russell Sage Foundation, New York. 
Camerer, C. F., Ho, T-H. and Chong, J-K. 2004. A cognitive hierarchy model of games. Quarterly Journal of Economics. 119 (3) 861-898.

Chandy, R. and Tellis, G. 2000. The incumbent's curse? Incumbency, Size and Radical Product Innovation. Journal of Marketing. 67 (3) 1-17

Chandy, R., J. Prabhu and K. Antia. 2003. What will the future bring? Dominance, Technology Expectations and Radical Innovations. Journal of Marketing. 67 (July) 1-18.

Chen, Hsiao-Chi, Friedman W. James, Thisse, Jacques, Francois 1997. Bounded rational Nash equilibrium: A probabilistic choice approach. Games and Economic Behavior. 18 (1) 32-54.

Chesbrough, H., R. Rosenbloom. 2002. The role of the business model in capturing value from innovation: Evidence from Xerox corporation's technology spinoff companies. Industrial and Corporate Change. 11 (3) 529-555.

Christensen, C. 1997. Innovators Dilemma. Harvard Business School Press. Boston, MA

Conner, K. 1988. Strategies for Product Cannibalism. Strategic Management Journal. 9 (Special Issue) 9-26.

Costa-Gomes, M A., Crawford, V P. 2006. Cognition and behavior in two person guessing games: An experimental study. American Economic Review. 96 (5) 1737-1768.

Dasgupta, P., Gilbert, R. and Stiglitz, J. 1983. Strategic considerations in invention and innovation: The case of natural resources. Econometrica. 51 (5) 1439-1448.

DeGroot. M.H. 1975. Probability and Statistics. Addison-Wesley. Reading, Mass.

Etro, F 2004. Innovation by Leaders. The Economic Journal. 114 (3) 282-303 
Gilbert, R., Newbery, D. 1982. Preemptive patenting and the persistence of monopoly. American Economic Review. 72 (3) 514-26

Farrell., S. Garth, 1988. Coordination through committees and markets. Rand Journal of Economics. 19 (2) 235-252.

Haile, P A,. Hortacsu, A., Kosenok, G. 2008. On the empirical content of quantal response equilibrium. American Economic Review. 98 (1) 180-200.

Harsanyi, J C. 1973. Games with randomly distributed payoffs: a new rationale for mixed strategy equilibrium points. International Journal of Game Theory. 2 (July) 1-23

Harsanyi, J C 1982. Subjective probability and the theory of games: Comments on Kadane and Larkey's paper. Management Science. 28 (2) 120-124.

IRI and Morgan Stanley Equity Research. 2003. IRI Data: Larger Volumes Declines in January, Eastman Kodak. Company Update, February. 1-13.

Janssen, M. 2008. Evolution of cooperation in a one-shot Prisoner's Dilemma based on recognition of trustworthy and untrustworthy agents. Journal of Economic Behavior \& Organization. 65 (3/4) 458-471.

Kadane, J B., P. D. Larkey. 1982. Subjective probability and the theory of games. Informs. Hanover, MD.

Kadane, J B., P. D. Larkey. 1983. The confusion of is and ought in game theoretic contexts. Management Science. 29 (12) 1365-1379.

Kaldor, N. 1972. The Irrelevance of Equilibrium Economics. The Economic Journal. 82 (328) $1237-1255$ 
Kamien, M.I., L.S. Schwartz. 1978. Potential Rivalry, Monopoly Profits and the Pace of Inventive Activity. Review of Economic Studies. 45 (November) 547-557.

Kaplan, S., R. Henderson. 2005. Inertia and incentives: Bridging organizational economics and organizational theory. Organization Science. 16 (5) 509-521.

Lerner, J. 1997. An Empirical Explanation of a Technological Race. Rand Journal of Economics. 28 (2) $228-247$.

Luce, D. R. 1959. Individual Choice Behavior.Wiley. New York.

McKelvey, R. D., R. P. Palfrey. 1995. Quantal response equilibria for normal form games. Games and Economic Behavior. 10 (1): 6-38.

McKinsey 2008. Assessing Innovation Metrics. The McKinsey Quarterly. 1 (Oct) 3-11.

Morris, S. 2008. Purification. The New Palgrave Dictionary of Economics, Second Edition. Steven N. Durlauf and Lawrence. E. Blume eds. Basingstoke and New York: Palgrave Macmillan.

Nault, B. , M.B. Vandenbosch. 1996. Eating your own lunch: Protection Through Preemption. Organisation Science. 7 (3) (May-June) 342-358.

Rabin, M. 1993. Incorporating Fairness into Game Theory and Economics. American Economic Review. 83 (5). 1281-1302.

Reinganum, J. 1983. Uncertain innovation and the persistence of monopoly. American Economic Review. 73(4) 741-8.

Rios Insua, D., Rios, J., and Banks, D. 2009. Adversarial risk analysis. Journal of the American Statistical Association. 104 841-854. 
Robinson, J. 1974. History versus equilibrium. Chapter 4 of Collected Economic Papers Volume Five. Basil Blackwell, Oxford. 48-58.

Roth, A., F. Schoumaker. 1983a. Subjective probability and the theory of games. Management Science. 29 (11) 1337-1340.

Roth, A,, F. Schoumaker. 1983b. Expectations and reputations in bargaining: An experimental study. American Economic Review. 73 (3) 362-372.

Selten, R. and T. Chmura. 2008. Stationary concepts for experimental $2 \times 2$ games. American Economic Review. 98(3) 938-966

Schumpeter, J.A. 1975. Capitalism, Socialism and Democracy. Harper and Row, Harper Colophon Ed. New York.

Teece, D.J., 1986. Profiting from technological innovation. Research Policy. 15 (6) 285-305.

Van Huyck, J B., R C. Battalio, and R. O. Beil 1990. Tacit coordination games, strategic uncertainty, and coordination failure. American Economic Review. 80 (1) 234-248.

Werner, F., Y.N. Sotskov. 2006. Mathematics of Economics and Business. Routledge, Oxford, United Kingdom.

Wilson, J G. 1986. Subjective probability and the prisoner's dilemma. Management Science. 32 (1) $45-55$. 